\title{
Chemicals for Protecting Corn Crops from Cotton Budworm
}

\section{Zaira Lionovna and Lyudmila Mikhailovna}

Plant Protection Laboratory, Institute of Agriculture - a branch of the Federal State Budget Scientific Institution Federal State Budgetary Scientific Institution Federal Scientific Center "Kabardino-Balkarian Scientific Center of the Russian Academy of Sciences" (Institute of Agricultural Sciences, KBSC RAS), Nalchik, Russian Federation

\section{ORCID:}

Zaira Lionovna: http://orcid.org/0000-0002-4873-2994

\section{Abstract}

Agrarian research is aimed at increasing crop yields by using modern agricultural technologies, including plant protection drugs. Certain corn pests have an annual distribution, but their harmfulness depends on overwintering and weather and climatic conditions in the spring and summer growing seasons. In 2016-2019, research was conducted to reduce the harmfulness of phytophages on corn crops. The species composition of the pests was studied and progressive species were identified. Second

Corresponding Author:

Zaira Lionovna

zaira_78h@mail.ru

Published: 5 April 2021

Publishing services provided by Knowledge E

(c) Zaira Lionovna and Lyudmila Mikhailovna. This article is distributed under the terms of the Creative Commons

Attribution License, which permits unrestricted use and redistribution provided that the original author and source are credited.

Selection and Peer-review unde the responsibility of the DonAgro Conference Committee.

\section{G OPEN ACCESS} generation cotton budworms damage corn crops. The most effective insecticides against cotton budworms were selected. Chemical insecticides and microbiological drugs were identified. With a timely double spraying of corn with Lepidocide, the biological efficiency was $80 \%$. Analyzing the data of insecticide tests, we have identified promising insecticides against cotton budworms that damage corn crops in the steppe arid zone of the Kabardino-Balkarian Republic.

Keywords: corn, phytosanitary monitoring, identification, cotton budworm, insecticides, economic efficiency, biological efficiency.

\section{Introduction}

The importance of pests as a factor that reduces the yield and safety of agricultural products increases when little attention is paid to creating an optimal phytosanitary environment through phenological observations and protective measures aimed at fighting against the most harmful phytophages.

It is known that as the production of seeds and grain develops, the efficiency of protecting corn crops from progressive harmful organisms becomes an important element of the cultivation technology. Therefore, the main research direction is the development of new elements in the system of regulation of the number of cotton budworms. 
In the conditions of the steppe arid zone of Kabardino-Balkaria, in some years, a high number of the cotton budworm population is revealed. Therefore, the loss of grain yield during the years of the outbreak of the cotton budworm reaches $60 \%$.

Cotton budworm - Helicoverpa armigera Hbn. (Lepidoptera, Noctuidae) is an insect that, due to its omnivorous nature, causes serious damage to many agricultural plants. It is widespread in the south of Russia, affecting the aboveground organs of corn, sunflower, soybeans, tomato, potato, etc.

\section{Research purpose, objectives, novelty}

The research is aimed at specifying the species composition of phytophages with subsequent phytosanitary monitoring of corn crops. A more environmentally friendly integrated corn budworm protection system is required for agriculture.

The aim of the research is to study the frequency of occurrences of cotton budworms and their effect on the yield and quality of corn crops.

In accordance with the goal, the following tasks were solved:

- to determine the species composition of phytophages on corn crops in the steppe arid zone and study their harmfulness;

- to test 12 chemical and two biological insecticides used to protect crops from cotton budworms;

- to identify insecticides that are most effective in the fight against cotton budworms;

- to assess the economic and biological effectiveness of insecticides used in the fight against second generation budworms.

The scientific novelty of the research is due to the fact that for the first time in the arid steppe zone of the Kabardino-Balkarian Republic, the biological effectiveness of insecticides used in the fight against cotton budworms damaging corn crops was determined. Of 14 biological and chemical insecticides, the most effective ones were determined.

\section{Methods and Materials}

Plot experiments were conducted in three replicates using the existing methods of plant protection [1 - 3].

Determinants were used to identify phytophages $[4,5]$.

Phytosanitary monitoring of experimental corn crops was carried out using the plant protection methods [4 - 6]. 
The calculation of the insecticide application rate was carried out according to the regulations of 2019 [7].

Peculiarities of soil and climatic conditions were identified according to the Adaptive Landscape System of Farming in the KBR [8].

This article continues scientific work aimed at specifying the biological effectiveness of promising insecticides [9-11].

\section{Discussion}

According to the phenological observations of the cotton budworm, the period for spraying was identified; it coincided with the beginning of ear flowering, when the second generation budworms begin to hatch. Asynchronous development of the cotton budworm stages usually contributes to the coincidence of the feeding activity of middle and older first generation budworms with the beginning of hatching of the second generation budworms.

In 2018, insecticides were tested in 25 variants of the experiment. Based on the results of these tests, ineffective insecticides were excluded. Therefore, the experiments conducted in 2019 were aimed to determine the biological effectiveness of 14 insecticides; drugs were used separately (12 variants) and in a mixture with other insecticides belonging to other groups of drugs ( 2 variants). The yield gain was determined in comparison with the control variant (without treatment).

7 days after spraying Terek corn hybrid, a comparative assessment of their biological effectiveness was carried out. In 2019, all tested insecticides had varying degrees of effectiveness; they were divided into three groups (Figure 1).

The first group includes new generation insecticides with a high value of biological effectiveness (88.6\% - 95.1\%): option 2 (Voliam Flexy, SK), option 3 (Belt, KS), option 4 (Avant, CE), option 5 (Proclame, VRG), option 6 (Coragen, KS), and option 14 (Ampligo, ISS).

The second group includes insecticides with an average value of biological effectiveness (68.5\% - 85.4\%): option 9 (Lepidocide, SK), option 10 (Lepidocide, SK + Karate Zeon, ISS), option 12 (Kinfos, CE), and option 13 (Decis Profi, VDG).

During three years of research, Bioinsecticide - Lepidocide, SK has been effective in the fight against cotton budworms. Its biological efficiency was 83.6\%. Unlike chemical insecticides, which were used only once (during the mass hatching of second generation 
budworms), Lepidocide, SC was used twice, with an interval of 6-7 days - at the beginning and mass hatching of budworms.

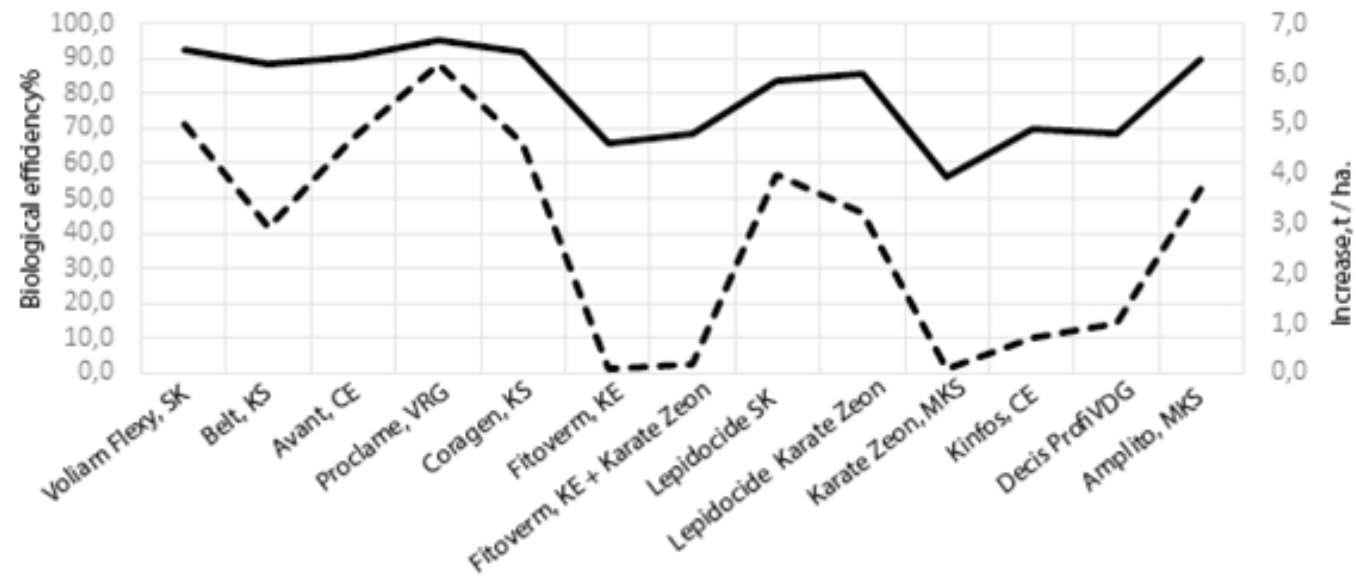

Biological efficiency (U1)

Gain, t/ha (U2)

Figure 1: Biological and economic efficiency of insecticides against caterpillars of cotton budworm on the Terek F1 maize hybrid (NPO 2 steppe zone KBR 2017-2018)

The group of weak insecticides with a low value of biological effectiveness - below 70\% - included the remaining options: 7 (Fitoverm, KE), 8 (Fitoverm, KE + Karate Zeon, MKS), 11 (Karate Zeon, MKS) and 13 (Decis Profi, VDG). Therefore, the costs of spraying with insecticides that fall into the third group have not been justified.

In 2016-2019, the economic efficiency of insecticides was determined. The assessment was carried out according to the corn yield gain. Both in terms of the maximum yield gain and biological efficiency, there were the same variants with new generation insecticides which were used for three years: Voliam Flexy, SK (option 2); Belt, KS (option 3); Avant, CE (option 4); Proclame, VRG (option 5); Coragen, KS (option 6); Ampligo, ISS (option 14), and bioinsecticide - Lepidotsid, SK; the yield gain was: 5.0 t / ha; 2.9 t / ha; $4.7 \mathrm{t} / \mathrm{ha} ; 6.2 \mathrm{t} / \mathrm{ha} ; 4.6 \mathrm{t} / \mathrm{ha} ; 3.7 \mathrm{t} / \mathrm{ha}$ and $4.0 \mathrm{t} / \mathrm{ha}$, respectively. Good indicators of the yield gain were observed in options 10 (Lepidotsid, SK + Karate Zeon, CE), 12 (Kinfos, CE), 13 (Decis Profi, VDG), which amounted to $3.2 \mathrm{t} / \mathrm{ha}$; $0.7 \mathrm{t} / \mathrm{ha} ; 1.0 \mathrm{t} / \mathrm{ha}$, respectively. In options 7 (Fitoverm, KE), 8 (Fitoverm, KE + Karate Zeon, ISS) and 11 (Karate Zeon, ISS), the additional costs caused by the high cost of insecticides will be equal or lower than the expected net income. Spraying with these drugs is not economically justified, since the yield gain was insignificant or equal to the yield in the control option (without treatment) - $6.0 \mathrm{t} / \mathrm{ha:} 0.1 \mathrm{t} / \mathrm{h}$; $0.2 \mathrm{t} / \mathrm{ha}$ and $0.1 \mathrm{t} / \mathrm{ha}$, respectively. 
Thus, the most promising insecticides are Voliam Flexy, SK; Belt, SK; Avant, CE; Proclame, VRG; Coragen, KS. The double application of Lepidocide SK, for which the biological efficiency on the 7 th and 14th days after spraying ranged from $83.6 \%$ to $95.1 \%$ and the yield gain was $4.0 \mathrm{t} /$ ha, is efficient.

\section{Conclusion}

Based on the results of four-year research, the following conclusions can be drawn:

1. The species composition of phytophages damaging corn crops in the steppe arid zone and a progressive species $(\mathrm{H}$. armigera) have been identified.

2. The population of cotton budworm was determined and its harmfulness was studied.

3. Of 14 biological and chemical insecticides, the most effective ones were selected: Voliam Flexy, SK; Belt, KS; Avant, CE; Proclame, VRG; Coragen, KS; Ampligo, ISS and Lepidocid, SK (double spraying).

4. On the basis of the experimental studies, new knowledge on effective control of cotton budworms in the arid steppe zone of Kabardino-Balkaria was obtained; it has a scientific and practical value in the development of elements in the system of integrated corn protection from cotton budworms.

\section{References}

[1] Peresypkin, V. F., et al. (1989). Practicum on Experimental Techniques in Plant Protection. Moscow: Agropromizdat, pp. 22-25.

[2] Pospelov, S. M. (1988). Practicum on Plant Protection. Moscow: Agropromizdat, pp. 16-19.

[3] Govorov, D. N., Zhivykh, A. V. and Shchetinin, P. B. (2017). Experiments are a Visual Way to Compare Pesticides. Plant Protection and Quarantine, vol. 8, pp. 40-41.

[4] Akhremovich, M. B., et al. (1976). Identifier of Agricultural Pests for Damage to Cultivated Plants. Leningrad: Rossellit pp. 38-48.

[5] Artokhin, K. S. (2012). Pests of Agricultural Crops: Reference and EducationalMethodical Manual (Vol. I). Moscow: Niva, pp. 339-377.

[6] Goncharov, N. R., Kolychev, N. G. and Cherkasov, V. A. (1985). Organization of Plant Protection. Moscow: Rosselkhozizdat, pp.17-27. 
[7] Ministry of Agriculture (2019). Guide of Pesticides and Agrochemicals Permitted for Use on the Territory of the Russian Federation. Pp. 848.

[8] Chochaev, M. M. (2013). Features of the Adaptive - Landscape Farming System of the Kabardino-Balkarian Republic. Nalchik: Monograph, pp. 53-60.

[9] Khromova, L. M., Shipsheva, Z. L. and Khromova, D. A. (2018). How to Protect Corn Crops from Harmful Organisms. Plant Protection and Quarantine, vol. 12, pp. 29-31.

[10] Khromova, L. M., et al. Biodiversity of Pests in Grain Agrocenosis in KabardinoBalkaria. The European Proceedings of Social \& Behavioral Sciences, pp. 920-928.

[11] Shipsheva, Z. L. (2019). Search for New Drugs to Protect Corn Crops from Cotton Budworm. Plant Protection and Quarantine, vol. 12, pp. 26-27. 